
\title{
25 Research Soure \\ Treatment Outcomes and Predictive Factors for Multidrug-Resistant TB and HIV Coinfection in Rio De Janeiro State, Brazil
}

Marcela Lopes Bhering ( $\sim$ marbhering@gmail.com )

Universidade Federal do Rio de Janeiro Faculdade de Medicina https://orcid.org/0000-0002-1568-026X

Raquel Duarte

Universidade Do Porto

Afrânio Kritski

Universidade Federal do Rio de Janeiro Faculdade de Medicina

Research article

Keywords: multidrug-resistant tuberculosis, HIV, Treatment Outcome, Risk factors

Posted Date: August 10th, 2020

DOI: https://doi.org/10.21203/rs.3.rs-54252/v1

License: (1) (1) This work is licensed under a Creative Commons Attribution 4.0 International License. Read Full License

Version of Record: A version of this preprint was published at The International Journal of Tuberculosis and Lung Disease on April 1st, 2021. See the published version at https://doi.org/10.5588/ijtld.20.0887. 


\section{Abstract}

Background: This study aims to identify and compare factors associated with the unfavorable treatment of MDRTB patients with HIV coinfection in the State of Rio de Janeiro (RJ), Brazil.

Methods: A retrospective cohort study with data from TB-MDR patients notified between 2000 and 2016 in RJ. Clinical and epidemiological characteristics and treatment outcomes of patients with HIV positive, negative, and unknown were compared. Bivariate and multivariate Cox hazard regression analysis was conducted to identify factors associated with unfavorable treatment results in patients MDR-TB / HIV positive.

Results: Of 2,269 cases, 1,999 (88.1\%) had a negative result for HIV, 156 (6.9\%) positive and 114 (5.0\%) unknown. The proportion of unfavourable outcomes was $43.7 \%$ among HIV negative, $52.6 \%$ among HIV positive and $43.9 \%$ among HIV unknown. Regarding MDR-TB / HIV positive cases, the unfavorable outcomes more prevalent were loss to follow up (24.4\%) and death (23.1\%). Previous MDR-TB treatment was associated with unsuccess and death. Illicit drugs use was a risk factor for unsuccess and loss to follow up. The six-month culture conversion was a protective factor for unsuccess and death. Administration of antiretroviral therapy was a protective factor for unsuccess, death and failure. The risk of XDR-TB cases for failure was six times higher than that of MDR-TB patients. All XDR-TB / HIV positive cases had unfavorable outcomes.

Conclusions: Early identification and immediate initiation of appropriate treatment are key to reducing unfavorable outcomes among MDR-TB / HIV positive. The high proportions of loss to follow-up and death may reflect difficulties in monitoring treatment, due to poor integration between the TB and HIV programs. In addition, none of XDR-TB / HIV positive patient had therapeutic success, highlighting the urgency to incorporate new drugs for the treatment of multidrug-resistant TB by Brazil's Ministry of Health.

\section{Background}

Human Immunodeficiency Virus (HIV) infection and the growing number of drug-resistant tuberculosis (TB) patients constitute a significant challenge to the global elimination of TB. It is estimated that in $2018,8.6 \%$ (range, 7.4-10\%) of TB cases were among people living with HIV and 251 thousand deaths occurred in this group (1).

Treatment of multidrug-resistant tuberculosis (MDR-TB) (drug resistance at least isoniazid and rifampicin) and extensively drug-resistant tuberculosis (XDR-TB) (TB-MDR plus resistance to a fluoroquinolone and a second-line injectable drug) require the use of second-line drugs which are more expensive and more toxic for a longer period than drug-sensitive TB (2). In HIV-infected patients, treatment is even more challenging. There may be additional comorbidities and opportunistic infections, ingestion of more pills resulting from the co-administration of antituberculosis drugs and antiretroviral therapy (ART), potential additive side effects, and drug interactions (3).

Brazil ranks 20th worldwide in TB cases and 19th in terms of TB-HIV coinfection, being one of the 30 countries considered priority by the World Health Organization (WHO) for TB elimination in the world (1). The State of Rio de Janeiro (RJ), one of Brazil's most developed subnational units, stands out for having a poor performance in TB control. It has the second-highest incidence and mortality rates in the country, which in 2018 were 63.3 and 4.2 per 100 thousand inhabitants, respectively (4). Therefore, a better understanding of the association between HIV infection and MDR-TB is certainly needed. 
That said, this work aims to identify the factors associated with the unfavorable treatment of MDR-TB in patients with HIV coinfection in RJ. The paper will also consider failure, death and loss of follow-up as specific unfavorable outcomes.

\section{Methods}

Research design and data

Retrospective cohort study based on secondary data of patients who started treatment for MDR-TB between 2000 and 2016. The cohort was extracted from the Special Tuberculosis Treatment Information System (SITETB). SITETB is an electronic information system of the Ministry of Health $(\mathrm{MoH})$ of Brazil, used for the compulsory notification and follow-up of all TB cases unable to use the standard TB regimen (2RHZE/4RH) (5).

The CD4, CD 8 cell counts and viral load copies/ml, performed before or during the first month of treatment for MDR-TB, were collected from the AIDS Laboratory Database (SISCEL) or patients' medical records. ART data were collected from the Antiretroviral Control System Database (SICLOM) or medical records. An additional file shows the data in more detail [see Additional file 1].

\section{Treatment of MDR-TB and HIV/AIDS}

Brazil has a good record of treating HIV/AIDS and TB. The MoH has been distributing medicines for the prophylaxis and treatment of infections since the mid-1980s. A federal law enacted in 1996 guaranteed the right of all individuals with HIV/AIDS to receive medicines free of charge. Regarding antituberculosis drugs, since the 1960s distribution has been free in the country. TB cases diagnosed in the private sector are referrals to the public sector. Private pharmacies do not offer first or second-line TB drugs. Medicines are ordered and purchased centrally by the $\mathrm{MoH}$. Since 2000 the $\mathrm{MoH}$ has developed specific epidemiological actions for MDR-TB, with a protocol for treatment, notification and monitoring of drug resistance cases.

HIV/Aids and MDR-TB are treated and monitored separately. In Brazil, health units are classified according to their complexity. In primary health care (PHC), patients with TB are treated using a basic regimen, as well as those with minor adverse reactions. TB-HIV cases are treated at the secondary level, along with patients with severe adverse reactions, including hepatotoxicity. Patients with drug-resistant and seriously ill TB are treated at the tertiary level, which is composed of hospitals and outpatient referral centers (6).

An HIV positive patient diagnosed with MDR-TB is referred to outpatient referral services for specialist evaluation. An anti-HIV test is performed in PHC and should be offered to every patient diagnosed with TB, regardless of its presentation (pulmonary or extrapulmonary).

Until 2014, the treatment of HIV/AIDS infection was performed mainly at the secondary level. From 2014 onwards, the treatment of HIV/AIDS with low risk began to be decentralized for PHC. For patients with MDR-TB, guidance for treatment shared among specialists remained.

In active tuberculosis, the onset of ART was indicated around 30 days after starting TB treatment, regardless of the result of the CD 4 count $(7,8)$. In 2013 patients with CD $4<200$ cells $/ \mathrm{mm}^{3}$ or with signs of advanced immunodeficiency have to start ART within two weeks after starting treatment for TB (9). Since 2017 this 
recommendation is for patients with CD4 $<50$ cells $/ \mathrm{mm}$. In other patients, ART should begin on the 8th week. Concomitant initiation of treatment for both conditions is not recommended (10).

\section{Outcomes: definition of key terms}

Treatment outcomes were classified according to WHO recommendations (11). The former are mutually exclusive. "Cure" occurs when the patient has at least three negative cultures after the 12th month of treatment. "Complete treatment" is the case when the patient has completed the stipulated time for treatment, with favorable clinical and radiological evolution, but without the accompanying cultures. "Loss of follow-up" takes place when the treatment was interrupted for 2 consecutive months or more. "Failure" is the outcome if the patient had two or more positive cultures in three recommended ones after the 12th month of treatment or three consecutive positive cultures after the 12th month of treatment, at least 30 days apart. Failure can also be the case according to medical evaluation and decision to change treatment early due to clinical and radiological worsening. "Death" is the outcome whenever the patient died for any reason during treatment. The "unfavorable" outcome is the sum of patients who had results classified as death, failure or loss of follow-up. "Success" of treatment is the sum of patients who had the result classified as complete cure and treatment.

Independent variables

The following variables were included in the regression analyses: sex, being under 37 years old, having less than 8 years of schooling, race/color, diabetes, comorbidities (viral hepatitis, renal failure, neoplasia, silicosis, transplant, mental disorder, use long-term use of corticosteroids, users of TNF alpha inhibitors, seizures and other undefined drugs, use of illicit drugs, alcohol dependence, smoking, unemployment, drug resistance category (MDR-TB or XDR-TB), treatment regimen (standardized or individualized), type of drug resistance (primary, that is, patients with no history of previous treatment; or acquired, that is, patients already treated for TB for one month or more) (12), disease extension (presence of chest cavity and/or bilateral disease), previous MDR-TB treatment, use of ART, and six-month culture conversion (defined as those patients with at least two negative cultures by the sixth month of treatment).

The standardized treatment regimen for MDR-TB is recommended and applied in Brazil and must include at least one first-line oral drug, if susceptible, a fluoroquinolone, an injectable drug along with terizidone. Individualized regimens may include other drugs, such as clofazimine, linezolid, imipenem and isoniazid in high doses. They are restricted to patients with additional resistance to first-line drugs, pre-XDR, XDR-TB, and to patients who have had adverse events with standardized regimen (7).

Patients who had more than one treatment for MDR-TB registered with SITETB were considered to have had previous treatment for MDR-TB.

Only variables that had a maximum of $10 \%$ of missing values were selected. For this reason, the results of counting CD4, CD8 and HIV viral load were only described.

Statistical methods

Given the nature of the dependent variable, number (frequency) and median (interquartile range [IQR] 25\% -75\%) were used to describe the characteristics of the patients and the treatment outcome according to coinfection status (TB-MDR HIV negative, positive and unknown). Treatment outcomes were also described according to the 
drug resistance pattern (MDR or XDR-TB), and coinfection. The chi-square test $(\chi 2)$ or Fisher's exact test were used to compare the proportions between groups.

Cox proportional hazards models were implemented to estimate hazard rates (HR) between each of the treatment outcomes and the covariates in the MDR-TB HIV positive patient group. Variables with significance levels $\leq 0.20$ in the bivariate analysis were included in the multivariate model. The better adjusted model was chosen using the likelihood ratio test. A significance level of 0.05 was applied to all tests. The statistical analysis was conducted with STATA version 13.1 program.

\section{Results}

\section{Descriptive Analysis}

Between 2000 and 2016, 2,477 cases of MDR-TB were reported in RJ, with 208 cases excluded: 8 non-residents in RJ, 11 undergoing treatment, 3 unknown results, 11 changes in diagnosis and 175 drug-susceptibility testings not indicating resistance to, at least, rifampicin and isoniazid. Of the total of 2,269 cases, 1999 (88.1\%) had a negative result for HIV, 156 (6.9\%) positive and 114 (5.0\%) unknown. There were 1466 (64.6\%) male patients. Table 1 describes the sociodemographic and clinical variables relating to MDR-TB patients with HIV positive, negative, and unknown results.

Overall, the median age was 38 (IQR 28-49) years, whereas among HIV positive patients, the median was 37 (IQR $30-45)$. HIV positive cases also stand out for having $14.7 \%$ of cases with extrapulmonary or pulmonary/extrapulmonary MDR-TB, while in the HIV negative and unknown group they had, respectively, $1.3 \%$ and $2.6 \%$. In addition, HIV positive patients had a higher percentage of comorbidities (14.1\% [excluding diabetes]) than patients with negative and unknown HIV (11.9\% and 11.4\%). The groups with negative and unknown HIV had more cases with diabetes, $9.8 \%$ and $14.9 \%$, respectively, than the group with HIV positive, which had $3.2 \%$. Among the 22 HIV positive patients with comorbidities, the most prevalent types were viral hepatitis, mental disorder, neoplasia, and depression.

Unemployment was frequent within the groups, with 307 cases (15.4\%) within HIV negative cases, 42 (26.9\%) within HIV positive and 24 (27.0\%) within unknown HIV. The use of illicit drugs was reported in 30 (19.2\%) HIV positive patients, a higher percentage than among HIV negative and unknown patients, $6.9 \%$ and $10.5 \%$ respectively.

Among the 156 HIV positive patients, 137 (87.8\%) already had a diagnosis of HIV when they started MDR-TB treatment, 117 (75\%) had a CD4 record, and 88 (56.4\%) had a CD8 record available. The median of CD4 was 311 cells/mm3 (IQR 141-497), while the median of CD8 was 840.5 cells/mm3 (IQR 520.5-1204.5). HIV viral load was available in 65 (41.6\%) records, with a median of 8166 copies/ml (IQR 903-37,000). As for ART, 85 (66.4\%) had a treatment record during the treatment of MDR-TB.

Table 1. Demographic and clinical characteristics of 2,269 MDR-TB patients by HIV status 


\begin{tabular}{|c|c|c|c|c|}
\hline Characteristics & $\begin{array}{l}\text { HIV negative } \\
(\%)\end{array}$ & $\begin{array}{l}\text { HIV positive } \\
\text { (\%) }\end{array}$ & $\begin{array}{l}\text { HIV unknown (\%) } \\
\mathrm{N}=114\end{array}$ & p-value* \\
\hline & $N=1999$ & $N=156$ & & \\
\hline Sex & $670(34.8)$ & $61(39.1)$ & $47(41.2)$ & 0.226 \\
\hline Female & 1304 (65.2) & 95 (60.9) & $67(58.8)$ & $<0.001$ \\
\hline Male & $316(15.8)$ & $11(7.1)$ & 18 (15.8) & 0.155 \\
\hline Age Range & $975(48.7)$ & 104 (66.7) & $47(41.2)$ & 0.296 \\
\hline $0-24$ & $635(31.7)$ & $40(25.6)$ & $41(36.0)$ & $<0.001$ \\
\hline $25-44$ & $74(3.7)$ & $1(0.6)$ & $8(7.0)$ & 0.004 \\
\hline $45-64$ & $730(36.5)$ & 44 (28.2) & $42(36.8)$ & 0.399 \\
\hline$\geq 65$ & 1198 (60.0) & 106 (68.0) & $68(59.6)$ & $<0.001$ \\
\hline Ethnical group & $71(3.5)$ & $6(3.8)$ & $4(3.5)$ & 0.477 \\
\hline Caucasian & $95(4.7)$ & $13(8.3)$ & $5(4.4)$ & $<0.001$ \\
\hline Afro-Brazilian & $379(19.0)$ & 31 (19.9) & $20(17.5)$ & 0.695 \\
\hline Unknown & 771 (38.6) & 65 (41.7) & 43 (37.7) & $<0.001$ \\
\hline Years of study & $437(21.9)$ & 24 (15.4) & $30(26.3)$ & $<0.001$ \\
\hline None & $153(7.6)$ & $7(4.5)$ & $6(5.3)$ & 0.725 \\
\hline 1 a 3 & 164 (8.2) & 16 (10.2) & $10(8.8)$ & 0.026 \\
\hline 4 a 7 & $9(0.5)$ & $10(6.4)$ & $1(0.9)$ & 0.098 \\
\hline 8 a 11 & 1974 (98.7) & 133 (85.3) & $111(97.4)$ & 0.084 \\
\hline$\geq 12$ & $16(0.8)$ & 13 (8.3) & $2(1.7)$ & 0.019 \\
\hline Ignored & $197(9.8)$ & 5 (3.2) & $17(14.9)$ & 0.037 \\
\hline Site of disease & $243(12.2)$ & $14(9.0)$ & $16(14.0)$ & \\
\hline Extrapulmonary & 138 (6.9) & 30 (19.2) & $12(10.5)$ & \\
\hline Pulmonary & $170(8.5)$ & $10(6.4)$ & $12(10.5)$ & \\
\hline Both & $307(15.4)$ & $42(26.9)$ & $24(27.0)$ & \\
\hline Other factors & $237(11.9)$ & $22(14.1)$ & $13(11.4)$ & \\
\hline Diabetes & $1586(82.0)$ & $99(68.3)$ & $87(78.4)$ & \\
\hline Alcohol abuse & 1478 (76.4) & $108(74.5)$ & $62(56.4)$ & \\
\hline Illicit Drug use & $298(14.9)$ & $22(14.1)$ & $14(12.3)$ & \\
\hline Smoking & 1701 (85.1) & 134 (85.9) & $100(87.7)$ & \\
\hline \multirow[t]{2}{*}{ Unemployed } & 1550 (77.5) & 118 (75.6) & $76(66.7)$ & \\
\hline & $449(22.5)$ & $38(24.3)$ & 38 (33.3) & \\
\hline
\end{tabular}




$\begin{array}{|llll|}\text { Comorbidities }^{\dagger} & 1126(56.3) & 74(47.4) & 64(56.1) \\ \text { Chest radiography }(\mathrm{n}=2189) & 368(18.4) & 38(24.4) & 27(23.7) \\ \text { Cavitation } & 295(14.8) & 36(23.1) & 16(14.0) \\ \text { Bilateral } & 210(10.5) & 8(5.1) & 7(6.1) \\ \text { Drug Resistance type } & & & \\ \text { Primary } & & \\ \text { Acquired } & & \\ \text { Previous MDR-TB treatment } & & \\ \text { No } & \\ \text { Yes } & \\ \text { Outcomes } & \\ \text { Cured/Treatment completed } & \\ \text { Lost to follow up } & \\ \text { Died } \\ \text { Failed }\end{array}$

TB: tuberculosis; MDR-TB: multidrug-resistant TB; XDR-TB: extensively drug-resistant TB;

HIV: human immunodeficiency virus.

*Comparison between HIV negative, positive and unknown.

${ }^{\dagger}$ Except Diabetes and HIV.

In general, 1,005 (44.3\%) patients had unfavorable outcomes, being more frequent among HIV positive patients (52.6\%) than in HIV negative cases (43.7\%), and in HIV unknown (43.9\%). The most frequent variable associated with unfavorable treatment was lost to follow up, which occurred in 38 (24.4\%) cases with HIV positive, and in 395 (18.4\%) with HIV negative. Death affected 36 (23.1\%) of HIV positive cases, and 295 (14.8\%) of HIV negative. Failure was twice as high among HIV negative patients (10.5\%) as among HIV positive patients (5.1\%).

\section{Drug resistance and treatment outcomes}

Upon analysis of treatment outcomes by HIV status and drug resistance (see Table 2), MDR or XDR-TB, it was observed that MDR-TB patients, regardless of HIV serological status, have more therapeutic success. The success among XDR-TB HIV negative/unknown cases was only $20.8 \%$, while, in the same period, there was no case of therapeutic success among XDR-TB HIV positive cases. Death was more frequent in HIV positive, especially in XDR-TB patients, while failure was practically the same among XDR-TB groups, but it was lower among MDR-TB HIV positive (2.8\%) than among MDR-TB HIV negative cases (8.5\%).

Table 2: Treatment outcomes among 2,269 patients with MDR-TB and XDR-TB by HIV status 


\begin{tabular}{|lllllll|}
\hline Outcomes & \multicolumn{2}{l}{ HIV Negative/Unknown } & HIV Positive & & \\
\cline { 2 - 7 } & MDR & XDR & p-value & MDR & XDR & p-value $^{*}$ \\
& $(\mathrm{n}=1983)$ & $(\mathrm{n}=130)$ & & $(\mathrm{n}=145)$ & $(\mathrm{n}=11)$ & \\
\hline Cure/treatment completed & $1163(58.6)$ & $27(20.8)$ & $<0.001$ & $74(51.0)$ & $0(0.0)$ & 0.001 \\
Lost to follow up & $379(19.1)$ & $16(12.3)$ & 0.054 & $35(24.1)$ & $3(27.3)$ & 0.815 \\
Died & $273(13.8)$ & $38(29.2)$ & $<0.001$ & $32(22.1)$ & $4(36.4)$ & 0.278 \\
Failed & $168(8.5)$ & $49(37.7)$ & $<0.001$ & $4(2.8)$ & $4(36.4)$ & $<0.001$ \\
\hline
\end{tabular}

TB: tuberculosis; MDR-TB: multidrug-resistant TB; XDR-TB: extensively drug-resistant TB;

HIV: human immunodeficiency virus.

${ }^{*}$ Comparison between MDR/XDR-TB.

Among HIV positive patients who did not undergo ART, half died within the first 180 days after starting treatment for MDR-TB, while among those who did ART, the time span was 510 days. These patients were treated with a median of 5 drugs. The most common initial regimens included amikacin (65\%), streptomycin (28\%), ethambutol (92\%), clofazimine (25\%), terizidone (95.5\%), pyrazinamide (55\%), ofloxacin (47\%) and levofloxacin (44\%).

\section{Factors associated with treatment outcomes in MDR-TB patients with HIV coinfection in the bivariate model}

Bivariate analyses of the factors associated with unsuccess, loss to follow up, death and failure for HIV-positive MDR-TB patients are displayed in table 3. Unsuccess was more likely among illicit drug users (HR $1.64,95 \% \mathrm{Cl}$ 1.01-2.70), the unemployment (HR 1.73,95\% Cl 1.08-2.75), and patients with previous MDR-TB treatment (HR 1.97, $95 \% \mathrm{Cl} 1.22-3.19)$. Six-month culture conversion (HR 0.50, 95\% Cl 0.29-0.87) and receiving ART (HR 0.61, 95\% Cl 0.39-0.95) were protective factors for unsuccess. The loss to follow up was associated with the use of illicit drugs (HR 3.59, 95\% Cl 1.87-6.90), alcohol abuse (HR 2.30,95\% Cl 1.05-5.05), and being unemployed ( $\mathrm{HR} 2.08,95 \% \mathrm{Cl}$ 1.07-4.01). Risk factors for treatment failure were previous MDR-TB treatment (HR 5.13, 95\% Cl 1.23-21.41), and being XDR-TB (HR 6.47, 95\% CI 1.49-28.0), while ART (HR 0.16, 95\% CI 0.03-0.80) was a protective factor. For death, six-month culture conversion (HR 0.19, 95\% Cl 0.05-0.63) and ART (HR 0.37, 95\% Cl 0.18-0.73) were protective factors.

Table 3. Bivariate analysis: Predictors of unsuccessful, default and death among 156 MDR-TB HIV positive patients 


\begin{tabular}{|c|c|c|c|c|}
\hline \multirow[t]{2}{*}{ Predictors } & Unsuccess & Loss to follow up & Death & Failure \\
\hline & $\begin{array}{l}\mathrm{HR}(95 \% \mathrm{Cl}) p- \\
\text { value }\end{array}$ & $\begin{array}{l}\text { HR }(95 \% \mathrm{Cl}) p- \\
\text { value }\end{array}$ & $\begin{array}{l}\mathrm{HR}(95 \% \mathrm{Cl}) p- \\
\text { value }\end{array}$ & $\begin{array}{l}\mathrm{HR}(95 \% \mathrm{Cl}) p \text { - } \\
\text { value }\end{array}$ \\
\hline Sex & 1.0 & 1.0 & 1.0 & 1.0 \\
\hline Female & $\begin{array}{l}0.89(0.57-1.39) \\
0.621\end{array}$ & $\begin{array}{l}0.84(0.44-1.62) \\
0.622\end{array}$ & $\begin{array}{l}1.05(0.53-2.10) \\
0.875\end{array}$ & $\begin{array}{l}0.62(0.15-2.50) \\
0.508\end{array}$ \\
\hline Tvic & 1.0 & 1.0 & 1.0 & 1.0 \\
\hline No & $\begin{array}{l}1.35(1.07-3.52) \\
0.186\end{array}$ & $\begin{array}{l}1.66(0.86-3.29) \\
0.127\end{array}$ & $\begin{array}{l}2.16(0.83-5.59) \\
0.112\end{array}$ & $\begin{array}{l}2.78(0.34-22.6) \\
0.339\end{array}$ \\
\hline Yes & 1.0 & 1.0 & 1.0 & 1.0 \\
\hline Years of schooling & $\begin{array}{l}1.16(0.63-2.13) \\
0.619\end{array}$ & $\begin{array}{l}1.10(0.47-2.53) \\
0.819\end{array}$ & $\begin{array}{l}1.19(0.45-3.16) \\
0.717\end{array}$ & $\begin{array}{l}1.64(0.19-13.7) \\
0.646\end{array}$ \\
\hline $\begin{array}{l}\geq 8 \\
<8\end{array}$ & 1.0 & 1.0 & 1.0 & 1.0 \\
\hline Afro-Brazilian & $\begin{array}{l}1.22(0.73-2.01) \\
0.438\end{array}$ & $\begin{array}{l}1.39(0.66-2.96) \\
0.381\end{array}$ & $\begin{array}{l}0.91(0.44-1.89) \\
0.811\end{array}$ & $\begin{array}{l}3.66(0.44-30.0) \\
0.227\end{array}$ \\
\hline No & 1.0 & - & 1.0 & - \\
\hline Yes & $\begin{array}{l}0.26(0.03-1.91) \\
0.188\end{array}$ & 1.0 & $\begin{array}{l}0.63(0.08-4.68) \\
0.656\end{array}$ & - \\
\hline Diabetes & 1.0 & $\begin{array}{l}1.39(0.61-3.17) \\
0.431\end{array}$ & 1.0 & 1.0 \\
\hline $\begin{array}{l}\text { No } \\
\text { Yes }\end{array}$ & $\begin{array}{l}1.12(0.60-2.07) \\
0.717\end{array}$ & 1.0 & $\begin{array}{l}1.09(0.42-2.84) \\
0.849\end{array}$ & $\begin{array}{l}1.79(0.35-8.99) \\
0.476\end{array}$ \\
\hline Comorbidities & 1.0 & $\begin{array}{l}3.59(1.87-6.90) \\
<0.001\end{array}$ & 1.0 & 1.0 \\
\hline No & $\begin{array}{l}1.64(1.01-2.70) \\
0.048\end{array}$ & 1.0 & $\begin{array}{l}0.40(0.12-1.36) \\
0.142\end{array}$ & $\begin{array}{l}1.91(0.22-16.08) \\
0.548\end{array}$ \\
\hline $\begin{array}{l}\text { Yes } \\
\text { Illicit drug use }\end{array}$ & 1.0 & $\begin{array}{l}2.30(1.05-5.05) \\
0.037\end{array}$ & 1.0 & - \\
\hline No & $\begin{array}{l}1.26(0.67-2.37) \\
0.468\end{array}$ & $\begin{array}{l}1.0 \\
1.90(0.74-4.89)\end{array}$ & $\begin{array}{l}0.42(0.10-1.81) \\
0.251\end{array}$ & $\begin{array}{l}1.87(0.44-7.86) \\
0.390\end{array}$ \\
\hline Yes & 1.0 & 0.182 & 1.0 & 1.0 \\
\hline $\begin{array}{l}\text { Alcohol abuse } \\
\text { No }\end{array}$ & $\begin{array}{l}1.12(0.48-2.58) \\
0.788\end{array}$ & $\begin{array}{l}1.0 \\
2.08(1.07-4.01)\end{array}$ & $\begin{array}{l}0.45(0.06-3.31) \\
0.434\end{array}$ & $\begin{array}{l}0.25(0.03-2.05) \\
0.198\end{array}$ \\
\hline & 1.0 & 0.029 & 1.0 & 10 \\
\hline $\begin{array}{l}\text { Yes } \\
\text { Smoking }\end{array}$ & $\begin{array}{l}1.73(1.08-2.75) \\
0.020\end{array}$ & 1.0 & $\begin{array}{l}1.28(0.61-2.70) \\
0.498\end{array}$ & $0.18(0.03-0.91)$ \\
\hline No & 1.0 & $\begin{array}{l}0.92(0.46-1.83) \\
0.820\end{array}$ & 1.0 & 0.038 \\
\hline Yes & $\begin{array}{l}0.50(0.29-0.87) \\
0.015\end{array}$ & 1.0 & $\begin{array}{l}0.19(0.05-0.63) \\
0.007\end{array}$ & $1.30(0.16-10.63)$ \\
\hline Unemployed & 1.0 & $\begin{array}{l}1.31(0.64-2.66) \\
0.446\end{array}$ & 1.0 & 0802 \\
\hline $\begin{array}{l}\text { No } \\
\text { Yes }\end{array}$ & $\begin{array}{l}1.05(0.66-1.67) \\
0.823\end{array}$ & 1.0 & $\begin{array}{l}1.24(0.60-2.55) \\
0.551\end{array}$ & $\begin{array}{l}1.0 \\
0.86(0.20-3.62) \\
0.841\end{array}$ \\
\hline
\end{tabular}




\begin{tabular}{|c|c|c|c|c|}
\hline $\begin{array}{l}\text { Six-month culture } \\
\text { conversion }\end{array}$ & 1.0 & $\begin{array}{l}1.52(0.54-4.31) \\
0.424\end{array}$ & 1.0 & - \\
\hline No & $\begin{array}{l}1.34(0.67-2.70) \\
0.400\end{array}$ & 1.0 & $\begin{array}{l}1.22(0.42-3.49) \\
0.705\end{array}$ & 1.0 \\
\hline Yes & 1.0 & $\begin{array}{l}1.53(0.72-3.27) \\
0.264\end{array}$ & 1.0 & $\begin{array}{l}5.13(1.23-21.41) \\
0.025\end{array}$ \\
\hline Treatment regimen & $\begin{array}{l}1.09(0.67-1.75) \\
0.719\end{array}$ & 1.0 & $\begin{array}{l}0.89(0.44-1.80) \\
0.755\end{array}$ & \\
\hline Individualized & 1.0 & $0.91(0.44-1.90)$ & 1.0 & $\begin{array}{l}6.47(1.49-28.0) \\
0.013\end{array}$ \\
\hline $\begin{array}{l}\text { Standardized } \\
\text { Drug Resistance type }\end{array}$ & $\begin{array}{l}1.17(0.68-2.05) \\
0.558\end{array}$ & 1.0 & $\begin{array}{l}1.21(0.52-2.80) \\
0.652\end{array}$ & \\
\hline Primary & 1.0 & $\begin{array}{l}1.75(0.87-3.51) \\
0.110\end{array}$ & 1.0 & $\begin{array}{l}0.16(0.03-0.80) \\
0.026\end{array}$ \\
\hline Acquired & $\begin{array}{l}1.97(1.22-3.19) \\
0.005\end{array}$ & 1.0 & $\begin{array}{l}1.73(0.81-3.67) \\
0.154\end{array}$ & \\
\hline No cavitation & 1.0 & $\begin{array}{l}1.10(0.34-3.61) \\
0.864\end{array}$ & 1.0 & \\
\hline Cavitation & $\begin{array}{l}1.60(0.83-3.08) \\
0.156\end{array}$ & 1.0 & $\begin{array}{l}1.24(0.43-3.61) \\
0.683\end{array}$ & \\
\hline Unilateral & 1.0 & $\begin{array}{l}1.04(0.52-2.07) \\
0.909\end{array}$ & 1.0 & \\
\hline Bilateral & $\begin{array}{l}0.61(0.39-0.95) \\
0.029\end{array}$ & & $\begin{array}{l}0.37(0.18-0.73) \\
0.004\end{array}$ & \\
\hline $\begin{array}{l}\text { Previous MDR-TB } \\
\text { Treatment }\end{array}$ & & & & \\
\hline No & & & & \\
\hline Yes & & & & \\
\hline $\begin{array}{l}\text { Categories of drug } \\
\text { resistance }\end{array}$ & & & & \\
\hline MDR-TB & & & & \\
\hline XDR-TB & & & & \\
\hline ART & & & & \\
\hline No & & & & \\
\hline Yes & & & & \\
\hline
\end{tabular}

TB: tuberculosis; MDR-TB: multidrug-resistant TB; XDR-TB: extensively drug-resistant TB

HR: hazard rates; Cl: confidence interval

HIV: human immunodeficiency virus

ART: antiretroviral therapy

${ }^{\dagger}$ Except Diabetes and HIV

The multivariate model: Factors associated with treatment outcomes in MDR-TB patients with HIV coinfection 
In the final model, having previous MDR-TB was associated with unsuccess (HR 1.91 Cl 95\% 1.18-3.09 $\mathrm{p}=0.008$ ), and death (HR $2.99 \mathrm{Cl} 95 \% 1.22-7.31 \mathrm{p}=0.016)$. Use of illicit drugs was associated with unsuccess $(\mathrm{HR} 1.63 \mathrm{Cl}$ $95 \%$ 0.98-2.71 $\mathrm{p}=0.055$ ) and had three times more risk of loss to follow up (HR 3.25 Cl 95\% 1.67-6.31 $p=0.001)$. Being XDR-TB had six times more risk than MDR-TB for failure (HR 6.11 Cl 95\% 1.41-26.32 p = 0.015). Six-month culture conversion was a protective factor for unsuccess (HR 0.46 CI95\% 0.26-0.80 p = 0.007) and death (HR 0.30 Cl95\% 0.08-1.03 $\mathrm{p}=0.056$ ), while ART was a protective factor for unsuccess (HR 0.58 Cl95\% 0.37-0.91), death (HR $0.38 \mathrm{Cl} 95 \%$ 0.16-0.92 $\mathrm{p}=0.034$ ), and failure (HR 0.15 Cl 95\% 0.03-0.78 p = 0.024) (Table 4).

Table 4. Multivariate analysis: Predictors of unsuccessful, default and death among 157 patients with HIV positive.

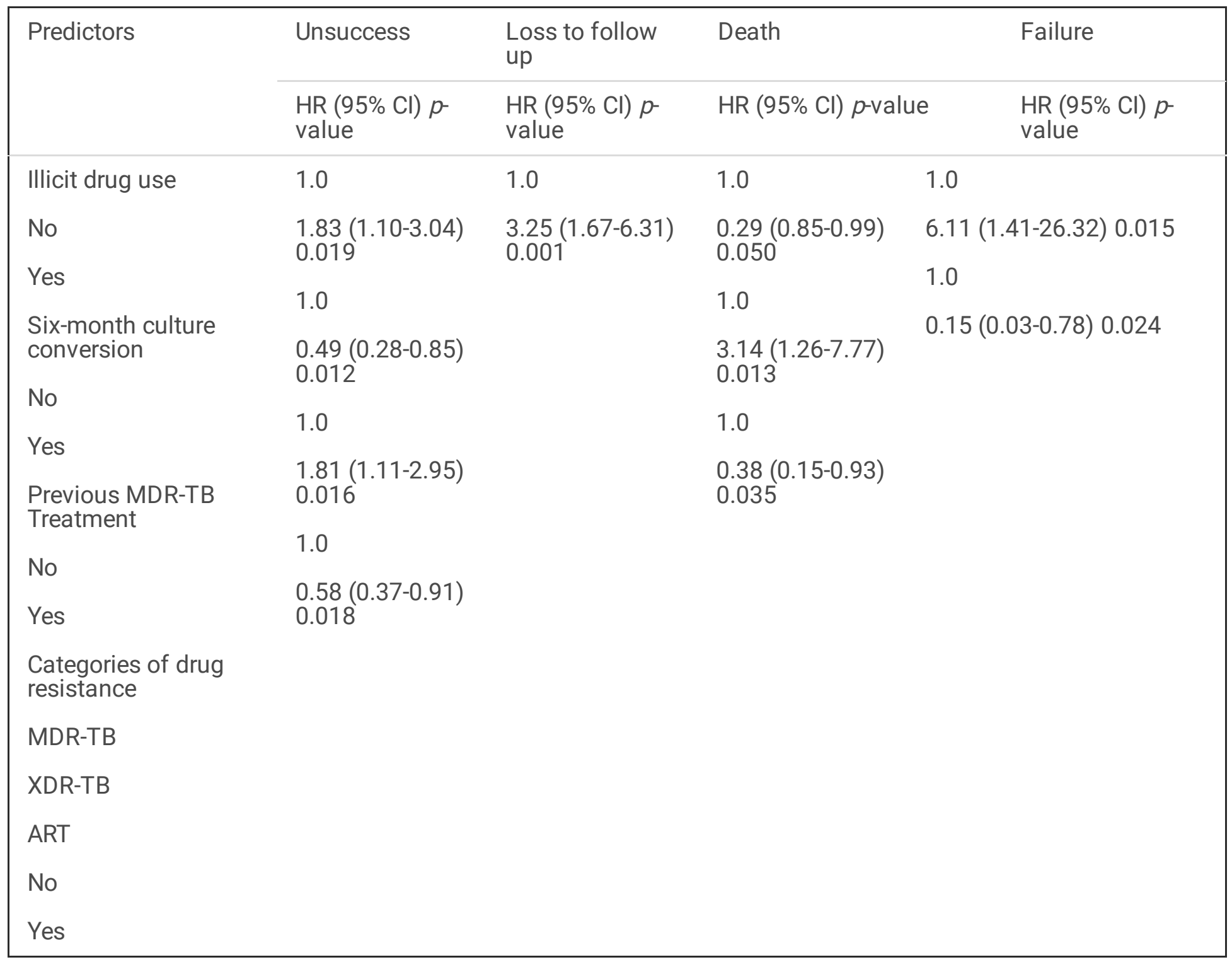

TB: tuberculosis; MDR-TB: multidrug-resistant TB; XDR-TB: extensively drug-resistant TB;

HR: hazard rates; $\mathrm{Cl}$ : confidence interval

HIV: human immunodeficiency virus.

ART: antiretroviral therapy 


\section{Discussion}

In the present study, unfavorable outcomes were more frequent among HIV positive patients (52.6\%) than among HIV negative cases (43.7\%), and HIV unknown (43.9\%). Lost to follow up (24.4\%) and death (23.1\%) were the unfavorable outcomes more frequently found among patients MDR-TB HIV positive. The use of illicit drugs and previous MDR-TB treatment were risk factors for unsuccess. ART and six-month culture conversion were protective factors. All of XDR-TB/HIV positive cases had an unfavorable outcome.

Among the 2,269 cases analyzed, the proportion of MDR-TB/HIV coinfection was $6.9 \%$. In 2016, according to MoH, the national rate of HIV coinfection among new TB cases was $9.4 \%$. In the same year, the proportion for the state of RJ was $8.7 \%$ (13). There is little data on MDR-TB/HIV coinfection in Brazil. In a study conducted with MDR-TB patients from all over the country, $9 \%$ of coinfection was observed (14), while another study conducted in a reference hospital in the city of São Paulo found $4 \%$ (15).

In general, in the present study, it was observed a therapeutic success rate of $56.3 \%$ among MDR-TB HIV negative cases and $47.4 \%$ among HIV positive cases. Recently, in a meta-analysis with 271 publications, including 3,368 MDR-TB HIV positive participants from Sub-Saharan Africa, treatment success was $44.8 \%$ (16).

Regarding unfavorable treatment outcomes, loss of follow-up was higher among HIV positive cases $(24.4 \%)$ than among HIV negative cases (18.4\%). According to WHO, the Americas has the highest proportion of cases with loss of follow-up, with $26 \%$ among MDR and rifampicin-resistant TB cases, while at the global level it is $14 \%$ (17). Although treatment is free of charge for both TB and HIV/AIDS in Brazil, the treatment generates extra costs such as food and access to services that consume a significant percentage of the income of the poorest patients (18). In addition, the scenario is aggravated by the barriers encountered by TB patients in accessing social protection measures. A study conducted with patients at a referral center for the MDR-TB treatment showed that only $38 \%$ of the participants reported being beneficiaries of social protection (19). A meta-analysis of low- and middle-income countries showed that social protection measures are associated with successful treatment and reduced lost of follow-up, in addition to being associated with a lower risk of impoverishment (20).

In our study, being an illicit drugs user (IDU) was a risk factor for treatment failure (HR 1.83 95\% Cl 1.10-3.04 p = $0.019)$, and generated three times more risk for loss of follow-up $(1.67-6.31 p=0.001)$. Although there is no specification on the type of drug, several studies have described the association between TB, HIV, and the illicit drugs use, whether injectable or not (21-25). Illicit drug use is often associated with other risk factors for TB, such as smoking, alcohol abuse, and incarceration (26). Thus, important additional barriers remain in the treatment of TB in this group. Therefore, Illicit drug users have more difficulty completing medical evaluations or adhering to Treatment for TB (3) and, when symptomatic, tend to wait longer to start appropriate treatment (27). A study conducted in the United States of America showed that, at the time of AIDS diagnosis, patients with a history of injecting drugs were 3.5 times more likely (95\% Cl 1.3-10.2) to have an opportunistic infection, including TB (28). This suggests that there is a lower demand for health care among IDUs, which, by its turn, can lead to more severe illnesses and contribute to an increase in TB transmission rates (29).

The challenge of maintaining high levels of adherence among IDUs highlights the current challenges facing TB elimination, which may require the provision and coordination of TB and Mental Health services with experience in handling illicit drug users, including targeted testing and treatment (30).

Page 12/18 
The proportion of death among MDR-TB HIV positive patients (23.1\%) was also higher than among HIV negative cases (14.8\%). Several studies report higher mortality and lower mean survival among MDR-TB HIV positive patients as compared to those without infection (31-34). A meta-analysis that included 22 studies showed that MDR-TB HIV positive patients had 1.6 times (95\% Cl: 1.38-1.99; I2 = 74\%, $p$ <.001) more risk of death than HIV negative. The same study also showed that unfavorable outcome among people living with HIV is greater in lowincome regions ( $\mathrm{RR} 2.23,95 \% \mathrm{Cl} 1.60-3.11$ ) than in high-income regions ( $\mathrm{RR} 1.22,95 \% \mathrm{Cl} 0.97-1.53$ ) (30). This indicates that socio-environmental issues and lack of access to health care can increase the vulnerability of this group.

In this study, the median of CD4 had a lower count than 350 cells $/ \mathrm{mm}^{3}$. This suggests late access for these patients to health services, reflecting on a greater chance of death. The late diagnosis of TB, inadequate management of MDR-TB, and limitations on access to ART are factors that contribute to a higher mortality rate in this group (35). However, early identification and the immediate initiation of appropriate anti-TB treatment and ART can reduce unfavorable outcomes among MDR-TB HIV positive patients (36). In the present study, ART was a protective factor against unsuccess (HR 0.58 CI95\% 0.37-0.91), death (HR 0.38 CI95\% 0.16-0.92 p = 0.034), and especially for failure (HR $0.15 \mathrm{Cl} 95 \% 0.03-0.78 p=0.024)$, showing that ART contributes to the reduction of unfavorable outcomes in patients with MDR-TB living with HIV.

Six-month culture conversion was also a protective factor against unsuccess (HR 0.46 Cl95\% 0.26-0.80 p = 0.007) and death (HR $0.30 \mathrm{CI} 95 \%$ 0.08-1.03 $\mathrm{p}=0.056)$. In studies with MDR-TB patients, it was observed that conversion status at six-month was significantly associated with treatment success as compared to failure or death. Among patients with successful treatment, the median time to culture conversion was significantly less than among those who had unfavorable results (37).

Finally, being XDR-TB HIV positive had six times more risk for failure (95\% Cl 1.41-26.32 $\mathrm{p}=0.015)$ than MDR-TB. None of the XDR-TB/HIV cases was successfully treated. The high rates of failure and death ( $36.4 \%$ each) within this group also reflect therapeutic limitations. This shows us the urgent need of the incorporation of new drugs by the $\mathrm{MoH}$ for the treatment of multidrug resistance. Likewise, issues related to the treatment and monitoring of patients must also be addressed.

In RJ, MDR-TB and HIV treatments are carried out in different health units, and the surveillance systems of the two diseases are not linked. This makes it difficult to monitor treatment and adverse events. Given the long duration of MDR/XDR treatment (18-24 months) and the large number of pills needed for concomitant treatment, close monitoring by healthcare professionals is necessary. Co-management of patients using ART and MDR/XDR drugs is complex and, therefore, it is essential that health professionals are trained to recognize potential and additive toxicity due to concomitant regimens.

In addition, measures at health services must be taken in order to promote the patient's commitment and adherence. Careful monitoring of patients is necessary to ensure that adverse effects are recognized quickly.

Finally, the present study has some limitations. As data were collected retrospectively, there was a lot of missing data on CD4, CD and HIV viral load. Besides, it was not possible to determine the period for starting ART. Also, due to the reduced number of records, it was not possible to assess the adverse events within the group of MDR/XDR HIV positive and their possible relationship with unfavorable outcome. Another fact that needs to be highlighted is that in the SITETB database, until 2015, variables related to diabetes, comorbidities, illicit drugs use, alcohol 
dependence, and smoking, whenever classified as "no," can also mean an absence of information. There is also no standardization for the classification of alcohol dependence, smoking, and mental health disorders. At any rate, the statistical findings reported here are robust due to the large sample size on which they are based.

\section{Conclusion}

The unfavorable results for MDR-TB HIV positive patients in RJ in 2000-2016 were associated with the illicit drugs use and previous treatment for MDR-TB. Six-month culture conversion and use of ART were protective factors.

This shows, on the one hand, that early identification and immediate initiation of appropriate treatment can reduce unfavorable outcomes among MDR-TB HIV positive patients. On the other, the high proportions of loss to followup (24.4\%) and death (23.1\%) may reflect difficulties in monitoring treatment, given the lack of integration between the TB and HIV programs. In addition, the fact that none of XDR-TB HIV patient had therapeutic success reflects the limitation of treatment options, and the urgency of Brazil's health system to incorporate new drugs in the treatment of multidrug resistance.

\section{Abbreviations}

HIV: Human Immunodeficiency Virus

TB: tuberculosis

MDR-TB: multidrug-resistant tuberculosis

XDR-TB: extensively drug-resistant tuberculosis

Cl: confidence interval

ART: antiretroviral therapy

WHO: World Health Organization

RJ: State of Rio de Janeiro

SITETB: Special Tuberculosis Treatment Information System

MoH: Ministry of Health

SISCEL: AIDS Laboratory Database

SICLOM: Antiretroviral Control System Database

PHC: primary health care

IQR: interquartile

HR: hazard rates

IDU: illicit drugs user 


\section{Declarations}

\section{Ethics approval and consent to participate}

The study protocol was approved by the Research Ethics Committee of the Federal University of Rio de Janeiro (CAAE 10126919.2.0000.5257), which granted permission for the use of the data appropriate for the purposes of the study, and waived the participants' written informed consent because the study was based on secondary data. All patients had an identification number and, to protect patients' confidentiality, only one investigator had access to the identified codes and prepared the anonymous database used in this study.

\section{Consent for publication}

Not applicable.

\section{Availability of data and materials}

The dataset supporting the conclusions of this article is included within the article and its Additional file 1.

\section{Competing interests}

The authors declare that they have no competing interests.

\section{Funding}

Not applicable.

\section{Authors' contributions}

$\mathrm{MB}$ and $\mathrm{AF}$ conceptualized and designed the study; RD contributed to the study methodology and interpretation of results; $\mathrm{MB}$ did the analysis and wrote the manuscript. All authors critically reviewed it. All authors read and approved the final manuscript.

\section{Acknowledgements}

We thank Dr Margareth Pretti Dalcolmo for comments and suggestions.

\section{References}

1. World Health Organization (WHO). Global Tuberculosis Report 2019. Geneva:WHO.2019.https://www.who.int/tb/publications/global_report/en/ Accessed 12 Mar 2020.

2. Raviglione MC, Smith IM. XDR Tuberculosis - Implications for Global Public Health. N Engl J Med. 2007;356(7):656.

3. Scano F, Vitoria M, Burman W, Harries AD, Gilks CF, Havlir D. Management of HIV-infected patients with MDRand XDR-TB in resource-limited settings. Int J Tuberc Lung Dis 2008; 12:1370.

4. Ministério da Saúde Brasil. Brasil Livre da Tuberculose: evolução dos cenários epidemiológicos e operacionais da doença. Bol Epidemiológico 2019;50(9):1.

5. Wilhelm D, Rodrigues MV, Nakata PT, Godoy SDC, Blatt CR. Descentralização do Acesso ao Sistema de Informações de tratamentos especiais em tuberculose. Rev Baiana Enfermagem. 2018;32:1. 
6. Bartholomay P, Pelissari DM, De Araujo WN, Yadon ZE, Heldal E. Quality of tuberculosis care at different levels of health care in Brazil in 2013. Rev Panam Salud Publica/Pan Am J Public Heal. 2016;39(1):3.

7. Brasil. Departamento de Vigilância Epidemiológica, Secretaria de Vigilância em Saúde, Ministério da Saúde. Manual de recomendações para o controle da tuberculose no Brasil. Brasília: Ministério da Saúde, 2011. http://bvsms.saude.gov.br/bvs/publicacoes/manual_recomendacoes_controle_tuberculose_brasil.pdf. Accessed 4 Apr 2020.

8. Brasil. Ministério da Saúde. Secretaria de Vigilância em Saúde. Coordenação Nacional de DST/AIDS. Recomendações para Terapia Anti-Retroviral em Adultos e Adolescentes infectados pelo HIV. Brasília: Ministério da Saúde, 2008. http://www.aids.gov.br/sites/default/files/pub/2016/59204/consensoadulto005c_2008montado.pdf. Accessed 4 Jul 2020.

9. Brasil. Ministério da Saúde. Secretaria de Vigilância em Saúde. Departamento de DST, Aids e Hepatites Virais. Protocolo Clínico e Diretrizes Terapêuticas para o Manejo da Infecção pelo HIV em Adultos. Brasília: Ministério da Sáude, 2013.

10. Brasil. Ministério da Saúde. Secretaria de Vigilância em Saúde. Departamento de DST, Aids e Hepatites Virais. Protocolo Clínico e Diretrizes Terapêuticas para o Manejo da Infecção pelo HIV em Adultos. Brasília: Ministério da Saúde, 2017. http://conitec.gov.br/images/Consultas/Relatorios/2017/Relatorio_PCDT_ManejolnfeccaoHIVadultos_CP.pdf. Accessed 20 Jul 2020.

11. World Health Organization (WHO): Companion handbook to the WHO guidelines for the programmatic management of drug resistant tuberculosis. Geneva: WHO. 2014. https://www.who.int/tb/publications/pmdt_companionhandbook/en/. Accessed 21 Jul 2020.

12. World Health Organization (WHO). Anti-tuberculosis drug resistance in the world: third global report/the WHO/IUATLD Global Project on Anti-Tuberculosis Drug Resistance Surveillance, 1999-2002. Geneva:WHO. 2004. https://apps.who.int/iris/handle/10665/43103. Accessed 19 Jun 2020.

13. Brasil. Ministério da Saúde. Secretaria de Vigilância em Saúde. Coinfecção TB-HIV no Brasil: panorama epidemiológico e atividades colaborativas. Brasília:Ministério da Saúde, 2017. http://www.aids.gov.br/ptbr/pub/2017/coinfeccao-tb-hiv-no-brasil-panorama-epidemiologico-e-atividades-colaborativas-2017. Accessed 20 Jul 2020.

14. Bastos ML, Cosme LB, Fregona G, do Prado TN, Bertolde Al, Zandonade E, et al. Treatment outcomes of MDRtuberculosis patients in Brazil: A retrospective cohort analysis. BMC Infect Dis. 2017;17(1):1.

15. Melo FAF, Afiune JB, Ide Neto J, Almeida EA, Spada DTA, Antelmo ANL, et al. Aspectos epidemiológicos da tuberculose multirresistente em serviço de referência na cidade de São Paulo. Rev Soc Bras Med Trop. 2003;36(1):27.

16. Chem ED, Van Hout MC, Hope V. Treatment outcomes and antiretroviral uptake in multidrug-resistant tuberculosis and HIV co-infected patients in Sub Saharan Africa: A systematic review and meta-analysis. BMC Infect Dis. 2019;19(1):1.

17. Pan American Health Organization (PAHO).Tuberculosis in the Americas, 2018. Washington, D.C.: PAHO. 2018. https://iris.paho.org/handle/10665.2/49510. Acessed 24 Jul 2020.

18. Tanimura T, Jaramillo E, Weil D, Raviglione M, Lönnroth K. Financial burden for tuberculosis patients in lowand middle-income countries: A systematic review. Eur Respir J. 2014;43(6):1763. 
19. Rudgard WE, Chagas NS, Gayoso R, Barreto ML, Boccia D, Smeeth L, et al. Uptake of governmental social protection and financial hardship during drug-resistant tuberculosis treatment in Rio de Janeiro, Brazil. Eur Respir J. 2018;51:1800274.

20. Andrade KVF de, Nery JS, Souza RA de, Pereira SM. Effects of social protection on tuberculosis treatment outcomes in low or middle-income and in high-burden countries: systematic review and meta-analysis. Cad Saude Publica. 2018;34(1):1.

21. Schultze A, Miller RF, Panteleev A, Skrahin A, Podlekareva DN, Miro JM, et al. Management of MDR-TB in HIV co-infected patients in Eastern Europe: Results from the TB:HIV study. J Infect. 2019;76(1):44.

22. Akksilp S, Wattanaamornkiat W, Kttikraisak W, Nateniyom S, Rienthong S, Sirinak C, et al. Multidrug-resistant TB and HIV in Thailand: overlapping, but not independently associated risk factors. Southeast Asian J Trop Med Public Health. 2009 Nov;40(6):1264.

23. Getahun H, Gunneberg C, Sculier D, Verster A, Raviglione M. Tuberculosis and HIV in people who inject drugs: evidence for action for tuberculosis, HIV, prison and harm reduction services. Curr Opin HIV AIDS. 2012;7:345.

24. Getahun H, Baddeley A, Raviglione M. Managing tuberculosis in people who use and inject illicit drugs. Bull World Health Organ. 2013;91:154.

25. Grenfell P, Baptista Leite R, Garfein R, de Lussigny S, Platt L, Rhodes T. Tuberculosis, injecting drug use and integrated HIV-TB care: a review of the literature. Drug Alcohol Depend. 2013;129:180.

26. Niveau G. Prevention of infectious disease transmission in correctional settings: a review. Public Health 2006; 120:33.

27. Diez M, Bleda MJ, Alcaide J, et al. Determinants of patient delay among tuberculosis cases in Spain. Eur J Public Health 2004; $14: 151$.

28. Hanna DB, Gupta LS, Jones LE, Thompson DM, Kellerman SE, Sackoff JE. AIDS-defining opportunistic illnesses in the HAART era in New York City. AIDS Care 2007; 19:264.

29. Golub JE, Bur S, Cronin WA, et al. Delayed tuberculosis diagnosis and tuberculosis transmission. Int J Tuberc Lung Dis 2006; 10:24.

30. Deiss RG, Rodwell TC, Garfein RS. Tuberculosis and illicit drug use: review and update. Clin Infect Dis 2009; 48:72.

31. Wells C D, Cegielski J P, Nelson L J, et al. HIV infection and multidrug-resistant tuberculosis: the perfect storm. J Infect Dis 2007; 196 Suppl 1:86-S107.

32. Isaakidis P, Casas EC, Das M, Tseretopoulou X, Ntzani EE, Ford N. Treatment outcomes for HIV and MDR-TB co-infected adults and children: systematic review and meta-analysis. Int J Tuberc Lung Dis 2015; $19(8): 969$.

33. Sungkanuparph S, Eampokalap B, Chottanapund S, Thongyen S, Manosuthi W. Impact of drug-resistant tuberculosis on the survival of HIV-infected patients. Int J Tuberc Lung Dis. 2007;11(3):325.

34. Seung KJ, Omatayo DB, Keshavjee S, Furin JJ, Farmer PE, Satti H. Early outcomes of MDR-TB treatment in a high HIV-prevalence setting in Southern Africa. PLoS One 2009; 4: e7186

35. Samuels JP, Sood A, Campbell JR, Ahmad Khan F, Johnston JC. Comorbidities and treatment outcomes in multidrug resistant tuberculosis: a systematic review and meta-analysis. Sci Rep. 2018;8(1):4980.

36. Magis-Escurra C, Günther G, Lange C, Alexandru S, Altet N, Avsar K, et al. Treatment outcomes of MDR-TB and HIV co-infection in Europe. Eur Respir J. 2017;49(6):30. 
37. Kurbatova EV, Cegielski JP, Lienhardt C, et al. Sputum culture conversion as a prognostic marker for end-oftreatment outcome in patients with multidrug-resistant tuberculosis: a secondary analysis of data from two observational cohort studies. Lancet Respir Med. 2015;3(3):201.

\section{Supplementary Files}

This is a list of supplementary files associated with this preprint. Click to download.

- Additionalfile1.xlsx 